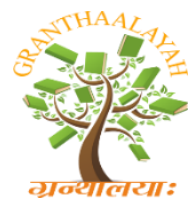

INTERNATIONAL JOURNAL OF RESEARCH GRANTHAALAYAH A knowledge Repository

Science

\title{
FORAMEN IN XIPHOID PROCESS OF STERNUM
}

\author{
Dr Anjali Sabnis ${ }^{1}$, Dr. Prakash Mane ${ }^{2}$ \\ ${ }^{1}$ Professor and head, Department of Anatomy, MGM Medical College, Navi Mumbai \\ ${ }^{2}$ Tutor, Department of Anatomy, MGM Medical College, Navi Mumbai
}

\begin{abstract}
Xiphoid process is smallest and distal component of manubrium sternum which is located in epigastrium. Variations in size and shape of xiphoid process are commonly observed. During teaching sternum to 1st M.B.B.S. students of MGM Medical College, Navi Mumbai, two small foramina in two different xiphoid processes were noticed. Though presence of foramen in xiphoid process is not uncommon, their presence should not be ignored. During assessment of injuries in autopsy, post-mortem examination and radiological reporting knowledge of xiphoid process and foramina in xiphoid process will be helpful.
\end{abstract}

Keywords: Foramen; Xiphoid Process; Manubrium; Sternum; Perforation.

Cite This Article: Dr Anjali Sabnis, and Dr. Prakash Mane. (2019). "FORAMEN IN XIPHOID PROCESS OF STERNUM." International Journal of Research - Granthaalayah, 7(12), 239-242. https://doi.org/10.29121/granthaalayah.v7.i12.2019.317.

\section{Introduction}

Sternum is a flat bone which forms anterior boundary of thoracic wall. Prosternum or manubrium, mesosternum or body and metasternum or xiphoid process are the three components of sternum. The distal and smallest component is xiphoid process which is located in epigastrium. Xiphoid process is derived from the Greek word "xiphos" means straight sword ${ }^{1}$. It articulates with body of sternum and forms xiphisternal joint. It is symphysis type of joint which usually gets transformed into synostosis variety of joint at the age of 40 years. The exact age is highly variable ${ }^{2}$. Along with lateral border facet of xiphoid process, inferior angle of lower part of body of sternum forms a common facet for $7^{\text {th }}$ intercostal cartilage. Medial fibres of rectus abdominis and aponeurosis of external and internal oblique muscle are attached to anterior surface of xiphoid process and aponeurosis of internal oblique and transversus abdominis is attached to lateral border of xiphoid process. On the posterior surface it is related to diaphragm in the lower region, transversus thoracic at the margin and costoxiphoid ligament ${ }^{3}$. Phrenic nerve $(C 3,4,5)$ supply to the two fleshy slips of diaphragm arising from back of the xiphoid process in addition to the lower intercostal nerves ${ }^{2,3}$. Variations in size, shape of xiphoid process are seen often. Xiphoid process can be straight, curved, bifid, pointed, thin and broad. 
Variations in xiphoid process should be kept in consideration so that they will not be confused with pathological conditions. The knowledge of variations may be important for academic and research purpose.

\section{Materials and Methods}

During teaching sternum to $1^{\text {st }}$ M.B.B.S students of MGM Medical College, it was observed that 2 xiphoid processes of two sternum have small centrally located foramina.

\section{Observation}

Length of $1^{\text {st }}$ sternum is $13.1 \mathrm{~cm}$ and $2^{\text {nd }}$ sternum is $13 \mathrm{~cm}$

Breadth of $1^{\text {st }}$ sternum is $2.9 \mathrm{~cm} 2^{\text {nd }}$ sternum is $2.1 \mathrm{~cm}$

Thickness of $1^{\text {st }}$ sternum is $8 \mathrm{~mm}$ and $2^{\text {nd }}$ sternum is $5 \mathrm{~mm}$. Foramen in $1^{\text {st }}$ xiphoid process is $4 \mathrm{~mm}$ $\mathrm{x} 2 \mathrm{~mm}$ and in $2^{\text {nd }}$ xiphoid process is $2 \mathrm{~mm} \times 2 \mathrm{~mm}$

The distance of the foramen from sternal angle is $\mathrm{mm}$ and in $2^{\text {nd }}$ sternum is $\mathrm{mm}$.

Both the foramina are located in the centre of xiphoid process. In the $2^{\text {nd }}$ sternum, xiphoid process is bifid.

Photograph showing foramen in two xiphoid processes (XP)

1A-Anterior surface of $1^{\text {st }}$ sternum

$1 \mathrm{P}$ - Posterior surface of 1 st sternum

$2 \mathrm{~A}$ - Anterior surface of $2^{\text {nd }}$ sternum

2P- Posterior surface of $2^{\text {nd }}$ sternum

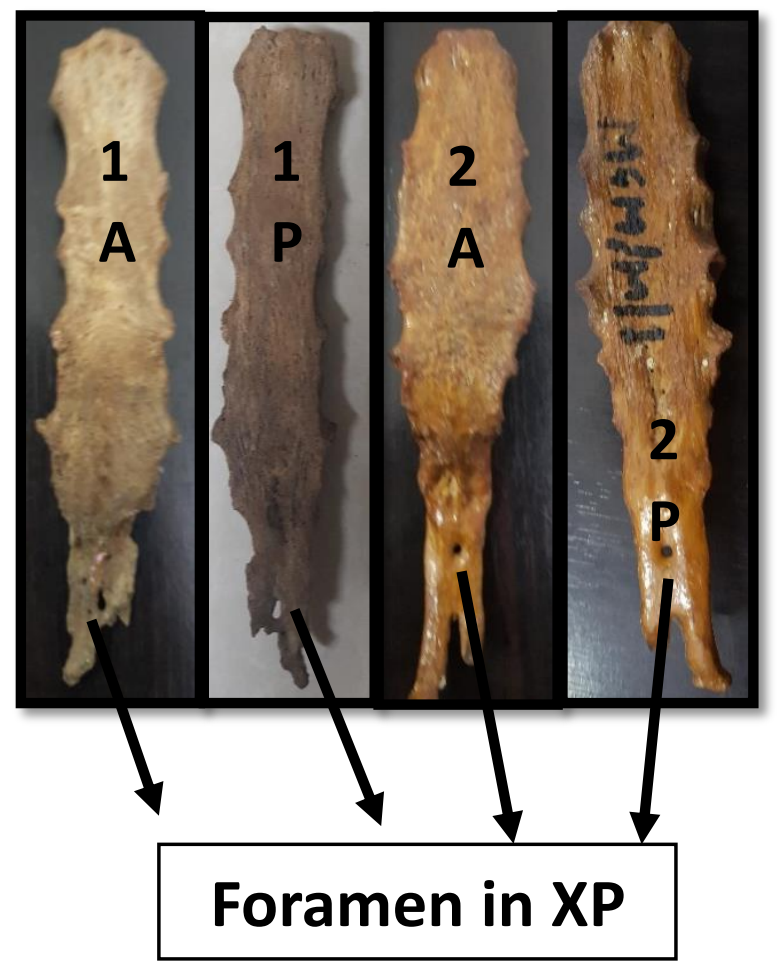




\section{Discussion}

Xiphoid process or xiphisternum is distal part of sternum which is cartilaginous initially and gets ossified in adults. Sternum develops from 6 centres, one for manubrium, four for body and one for xiphoid process ${ }^{4,5}$. Xiphoid process is formed by pair of mesenchymal condensation bands in the median plane anteriorly at the thoracic region. The primary centre of ossification for xiphoid process appears after birth during childhood at around $3^{\text {rd }}$ year of age ${ }^{1}$. Ossification of xiphoid process does not begin until the $5^{\text {th }}$ to $18^{\text {th }}$ year of life ${ }^{4,5}$. Initially the cartilage of xiphoid process unites with lower end of sternum by symphysis, a fibrous immovable joint with lower end of sternum at the age of 15 to 29 years ${ }^{1}$. Partial cartilaginization may persist into adult life. Thus, xiphoid abnormalities are rare as compared to manubrial defects ${ }^{4,5}$. Formation of foramen in xiphoid process may be because of incomplete fusion of pair of mesenchymal condensation and or incomplete ossification.

The pear-shaped foramen was present in the xiphoid process which resembled glenoid fossa of scapula. The maximum length of foramen was $1.6 \mathrm{~mm}$ and breadth $1.4 \mathrm{~mm}^{1}$. The incidence of single xiphoid foramen was $27.4 \%$ and double foramen was $27.2 \%$. The incidence of single xiphoid foramen was $3.5 \%^{7}, 2.5 \%^{8}, 34.5 \%^{9}$ and double foramen was $9 \%{ }^{9}, 4 \%{ }^{10}$. Pattern of xiphoid foramen was explained by Xie $\mathrm{YZ}^{11}$. As per that 4 patterns were explained on the basis of size of foramen. Incidence of L pattern (diameter more than $5 \mathrm{~mm}$ ) was $55.51 \%$, S pattern (diameter no more than $5 \mathrm{~mm}$ ) was $28.49 \%$, LS pattern (mixture of one large and one small) was $6.8 \%$, SS pattern ( 2 or more small foramen) was $9.19 \%{ }^{11}$. In the present case the size of foramen is very small. The size of foramen is $3.8 \mathrm{~mm}, 4.11 \mathrm{~mm}, 10.8 \mathrm{~mm}$ as maximum transverse diameter, $4.61 \mathrm{~mm}, 4.4 \mathrm{~mm}, 16.89 \mathrm{~mm}$ is vertical diameter ${ }^{10}$. In the present case foramen in $1^{\text {st }}$ xiphoid process is $4 \mathrm{~mm} \times 2 \mathrm{~mm}$ and in $2^{\text {nd }}$ xiphoid process is $2 \mathrm{~mm} \times 2 \mathrm{~mm}$.

Presence of foramen in xiphoid process may be asymptomatic. Because of attachment of muscles and ligaments to the xiphoid process, the foramen in the xiphoid process may not be palpable and visible on radiograph. But it is detected on $\mathrm{CT}$. If the size of foramen is bigger then it can be misinterpreted as gunshot injuries, fracture or lytic lesion. During performing acupuncture this foramen may lead to puncturing of parietal pleura and causes life threatening complication like pneumothorax. Morphological knowledge of sternum and xiphoid process and variations related to it is valuable for health care personal. Presence of xiphoid foramen with other congenital anomalies may be associated with genetic diseases and can be studied further. Thus xiphoid process anatomy may be interesting and important for academicians and researchers.

\section{References}

[1] Santhosh Kumar, Bravian, Anju Balaji More, Xiphoid foramen and its clinical implication, International Journal of Anatomy and Research, Int J Anat Res 2014, Vol 2(2):340-43. ISSN 23214287

[2] Moore KL, TVN Persaud: The developing human: clinically oriented embryology. 8th Ed. Elsevier Inc. Gurgaon, India. 2009: 360

[3] Standring S, Ellis H, Healy JC, et.al. Chest wall In: Standring S ed, Grays Anatomy: The anatomical basis of clinical practice.39th ed. London. Elsevier Churchill Livingstone, 2005: 952.

[4] H. L. Taylor, The sternal foramina: The possible forensic misinterpretation of an anatomic abnormality. Journal of forensic Sciences 1974;19(4):730-734 
[5] Chest wall \& breast; In: with associated Standring S, editor; Gray's Anatomy: The anatomical basis of clinical practice.40 th ed. Elsevier Churchill Livingstone, 2008: 917-918

[6] Yelekar E, Tunaci M, Tunaci A, Dursun M, Acumas G. Frequency of sternal variations and anomalies evaluated by MDCT.AJR Am J Roetgenol 2006, 186:958-960

[7] Shivkumar GL, Variations in the human sterna. Journal of evolution of medical and dental sciences, 2013, 2(2), 99-104

[8] El-Busaid, et al, Sternal foramina and variant xiphoid morphology in a Kenyan population. Folia Morphol (Warsz) 2012, 71(1) 19-22

[9] Akin K, Anatomic evaluation of the xiphoid process with 64 row multidetector computed tomography. Skeletal Radiol 2011,40(4):447-52

[10] Pasuk M, Anomalous foramen in the xiphoid process of the sternum: Anatomical considerations and clinical significance,

[11] Xie YZ, et al, Morphology of the human xiphoid process: dissection and radiography of cadavers and MDCT of patients. Surg Radiol Anat 2014,36(3): 209-17

\footnotetext{
*Corresponding author.

E-mail address: dranjus2003@ yahoo.com
} 